\title{
Capacidades conceituais na percepção
}

\author{
John McDowell \\ Universidade de Pittsburgh
}

resumo Um empirismo conseqüente depende da atribuição de um significado racional à nossa experiência perceptiva. Sem isto, a experiência perceptiva fica segregada do universo das crenças. Por outro lado, a experiência perceptiva não pode ser tratada como se fosse uma criação nossa. Ela deve ser vista como uma contribuição vinda de fora, que chega até nós através de nossos órgãos sensíveis. Estas duas exigências podem ser cumpridas desde que concebamos a experiência como a realização de capacidades conceituais na própria consciência sensivel.

palavras-chave experiência, percepção, capacidades conceituais, crenças, racionalidade.

\section{1.}

Nossas crenças baseadas na percepção são inteligíveis enquanto manifestações da racionalidade. Podemos lhes dar sentido estabelecendo um nexo explicativo entre elas e a experiência perceptiva. Quem tem uma crença baseada na percepção acredita em algo porque sua experiência the revela, ou ao menos parece lhe revelar, que as coisas são como ele acredita que sejam. Este "porquê" introduz uma explicação que depende da idéia de racionalidade operante.

Penso que atribuir esse significado racional à nossa experiência perceptiva é um insight fundamental do empirismo. Tentei mostrar que, para acomodá-lo, nós precisamos conceber nossa experiência perceptiva como uma realização, na consciência sensorial, de capacidades conceituais ${ }^{2}$.

Recebido em 15 de dezembro de 2005. Aceito em 23 de março de 2006.

Tradução de Herivelto Pereira de Souza.

doispontos, Curitiba, São Carlos, vol. 3, n. 1, p.147-170, abril, 2006 
Essa concepção de nossa experiência perceptiva possui alguma semelhança com a concepção kantiana de intuições empíricas. Na primeira Crítica $^{3}$ (de modo especialmente claro na Dedução Transcendental), Kant concebe as intuições empíricas como configurações da receptividade sensorial que estão categorialmente estruturadas. Para Kant, intuições são semelhantes a juízos neste ponto: o que torna possível seu teor objetivo é a sua unidade categorial. Traduzindo o pensamento kantiano num linguajar contemporâneo, diríamos que o conteúdo das intuições e o conteúdo dos juízos pertencem a um mesmo tipo. E é claro que o conteúdo dos juízos é conceitual.

Esse eco kantiano nos conduz ao tema da criatividade. Kant introduz o entendimento - a sede das capacidades conceituais - contrastando-o com a receptividade da sensibilidade. Ele descreve o entendimento como "a capacidade de produzir representações a partir de si mesmo, a espontaneidade do conhecimento" (KANT, 1929, A51/B75). Ainda mais diretamente, ele nos diz que conceitos "estão baseados na espontaneidade do pensamento" (KANT, 1929, A68/B93). Portanto, sua concepção das intuições empíricas associa o seu teor objetivo, que faz com que elas tornem os objetos imediatamente presentes para nós, à capacidade que ele nos atribui de autodeterminação espontânea no pensamento.

Voltarei a isto mais adiante, mas primeiro dedicarei alguma tempo a elaborar a concepção de experiência perceptiva que atribui esse papel ao entendimento espontâneo. Nossa principal tarefa será explicar a idéia relevante de capacidade conceitual. Isto exige que, antes, digamos algo a respeito da idéia de racionalidade.

\section{2.}

Eu afirmei que a crença baseada na percepção está ligada à experiência por um nexo explicativo que depende da idéia de operações da racionalidade. A noção de racionalidade que pretendo evocar aqui é a noção explorada por uma linha de raciocínio tradicional que dá aos animais racionais um lugar especial dentro do reino animal. Trata-se de uma noção de responsividade a razões enquanto tais. 
Esse modo de falar abre espaço para a responsividade a razões, mas não a razões enquanto tais, no outro lado da divisão estabelecida por essa noção de racionalidade entre animais racionais e animais que não são racionais. Animais de muitos tipos são capazes de, por exemplo, fugir, e fugir é uma resposta a algo que é, num sentido óbvio, uma razão para isso: um perigo, ou pelo menos algo que é visto como um perigo. Se nós descrevermos um comportamento como comportamento de fuga, nós o representaremos como inteligível à luz de uma razão para ele. Mas a fuga não está, de modo geral, respondendo a uma razão enquanto tal.

Para chegar à idéia de resposta a uma razão enquanto tal, precisaríamos considerar um sujeito capaz de recuar com respeito à sua inclinação para fugir, eliciada nele por um perigo aparente, e, além disso, capaz de perguntar se ele deveria ter essa inclinação - se o perigo aparente é, aqui e agora, uma razão suficiente para fugir. O que um animal faz decorre imediatamente de suas tendências motivacionais naturais, sem espaço para este tipo de reflexão, e, neste sentido, seu comportamento é determinado por sua natureza. Isso não implica negar que seu comportamento seja voluntário; e um animal, enquanto produtor de comportamento voluntário, não deve ser simplesmente identificado com os impulsos motivacionais que lhe vêm naturalmente. Neste tipo de caso, porém, a distinção entre o animal que se comporta de um certo modo e seus impulsos motivacionais não tem grande importância. Não faz muito sentido dizer que é o próprio animal que determina aquilo que ele faz. Por outro lado, considere uma pessoa que, diante da inclinação para a fuga que lhe sobreveio naturalmente, dá um passo atrás, e decide que a circunstância que elicia aquela inclinação é, de fato, uma razão suficiente para fugir. Se essa pessoa age a partir daquela razão, ela está se autodeterminando em sua ação.

Isso é apenas um exemplo, que deve dar uma idéia da concepção de racionalidade à qual eu quero recorrer. Obviamente, as razões para agir não estão restritas às circunstâncias capazes de eliciar naturalmente nossas inclinações, quando aquelas circunstâncias são transformadas em razões capazes de, enquanto tais, provocarem uma resposta - para um sujeito capaz de perguntar se é isso mesmo que elas são. E é claro que há também razões para crença.

Enfatizemos que o que importa é a capacidade de dar um passo para trás e avaliar se razões putativas dão garantia à ação ou à crença. Se 
alguém efetivamente dá um passo para trás, é claro que isso mostra que tem a capacidade para fazê-lo. Mas, se a capacidade está presente sem ser exercida, nós ainda assim estaremos diante de alguém capaz de responder a razões enquanto tais. A racionalidade no sentido em que a estou tomando pode estar operante mesmo que a capacidade de dar um passo para trás não esteja sendo exercida. Agir por uma razão, à qual se está respondendo enquanto tal, não requer que a pessoa reflita se tal consideração é mesmo uma garantia racional suficiente para algo que essa consideração parece recomendar. Basta que a pessoa seja capaz de fazer isso.

Considere alguém que caminha por uma trilha marcada e que, numa encruzilhada, toma a direita em resposta a uma seta apontando naquela direção. Seria absurdo dizer que ir à direita só é uma resposta racional à seta, caso essa ação resulte da determinação explícita, feita pela pessoa, de que a direção para a qual a seta está apontando lhe dá uma razão para ir à direita. O que importa é apenas que ela aja desse modo porque - e este é um "porquê" que introduz razões - a seta aponta para a direita. Isto se contrapõe, por exemplo, à suposição de que ela vire à direita por acaso, sem notar a sinalização, ou que a note, mas não a compreenda. O que mostra que ela vai para a direita dando uma resposta racional à direção em que a seta aponta poderia ser apenas que ela é capaz de responder posteriormente à questão de por que ela foi para a direita - uma questão que solicita suas razões para ter feito aquilo - dizendo "havia uma seta apontando para a direita". Ela não precisa ter sido advertida por essa razão, e ter decidido a partir dela.

Acho que é útil associar a idéia de capacidades conceituais a essa noção de racionalidade. Eu uso a idéia de capacidade conceitual de tal modo que ela é governada pela seguinte estipulação: capacidades conceituais, no sentido que me interessa, pertencem essencialmente à racionalidade de quem as possui, racionalidade no sentido com o qual estou trabalhando, de responsividade a razões enquanto tais.

O contexto primário para a idéia de responsividade a razões enquanto tais é dado pelo raciocínio: uma atividade na qual alguém explicitamente 
considera em que coisa crer ou o que fazer, e leva razões em conta na determinação de suas crenças ou de suas ações. Capacidades só podem estar em funcionamento nas operações da racionalidade, e só podem, portanto, ser capacidades conceituais no sentido de minha estipulação, em sujeitos que podem exercitar tais capacidades raciocinando. A habilidade para dar um passo para trás e avaliar se razões putativas são realmente razões - habilidade que explorei quando introduzi a idéia de responsividade a razões enquanto tais - é parte da habilidade para raciocinar. Assim, evocar o raciocínio é apenas dar um rótulo para o contexto no qual estou inserindo a idéia de responsividade a razões enquanto tais.

Se um animal tem em seu repertório o comportamento de fuga, ele deve ser capaz de discriminar (talvez não muito acuradamente) entre situações que o colocam em perigo e situações que não o colocam em perigo. Mas, dada minha estipulação, essa habilidade para discriminar não é suficiente para que ele tenha o conceito de perigo. O conceito requer um sujeito que pode responder à periculosidade enquanto a razão que ela é. $\mathrm{E}$ isto requer, em contrapartida, a habilidade para levar a periculosidade em conta no raciocínio.

Agora que introduzi o raciocínio, eu posso reformular uma afirmação que fiz mais acima da seguinte maneira: os casos nos quais alguém se põe a raciocinar não esgotam o âmbito de sua responsividade a razões enquanto tais. Considere novamente a pessoa que, sem parar para pensar no que fazer, toma a direita respondendo racionalmente a uma seta que aponta naquela direção. Até certo ponto, seu comportamento, irrefletido como é, é semelhante ao do animal que segue à direita após ter sido treinado para ir à direita em resposta a objetos com uma determinada forma. Esse animal adquiriu a habilidade para discriminar entre coisas que têm aquela forma e coisas que não têm. Porém, tal como ocorria com a habilidade para discriminar entre situações que trazem perigo e situações que não trazem, isto não é suficiente para caracterizar a posse do conceito de coisas que apontam para a direita. Ter um conceito requer a habilidade para levar em consideração no raciocínio que algo cai sob esse conceito. Nosso sujeito racional tem essa habilidade, ainda que não a exerça na ocasião que estamos considerando, quando vai à direita sem ter decidido fazer isso com base num raciocínio. E a capacidade conceitual, que a posse dessa habilidade nos permite atribuir-lhe, com o conceito de coisas 


\section{2}

que apontam para a direita como seu conteúdo, está operante também na resposta irrefletida que estamos considerando: uma resposta, não envolvendo raciocínio, a uma sinalização que aponta para a direita e é tomada como razão para ir à direita. Capacidades conceituais no sentido relevante estão em funcionamento não apenas no raciocínio, mas, de maneira geral, quando respondemos a razões enquanto tais, tenha ou não essa resposta a forma de uma extração explícita de conclusões a partir de razões quando formamos nossas crenças, ou quando agimos.

\section{4.}

Associei a responsividade a razões enquanto tais, e conseqüentemente as capacidades conceituais, ao raciocínio. Isto serviu para inserir a noção que me interessa de racionalidade no contexto de uma noção de inferência entendida de maneira suficientemente larga para cobrir tanto a ação em conseqüência do raciocínio prático, quanto a aquisição de uma certa crença em conseqüência do raciocínio teórico. Se alguém crê em algo ou age de uma certa maneira por alguma razão, esse alguém não precisa ter chegado à sua crença ou à sua ação por um passo inferencial. Até agora, limitei-me a considerar operações da racionalidade envolvendo estruturas que poderiam caracterizar inferências teóricas ou práticas a partir de razões para crenças ou ações.

Meu objetivo, porém, era explicar detalhadamente como a idéia de racionalidade está em jogo quando explicamos crenças perceptivas em termos da experiência. E aqui a noção de inferência não tem lugar. Quando alguém adquire uma crença dessa maneira, passa a crer que as coisas são como sua experiência lhe revela, ou ao menos parece revelar, que elas são. O conteúdo que a explicação atribui à experiência é idêntico ao conteúdo da crença explicada, e não uma premissa a partir da qual faria sentido pensar que o sujeito chegou à sua crença por meio de um passo inferencial ${ }^{4}$.

Isso não solapa a idéia de que tais explicações tornam as crenças inteligíveis enquanto resultados da racionalidade operante do sujeito. E aqui, também, trata-se de racionalidade no sentido que separa os animais racionais dos não-racionais, sentido que tentei capturar em termos de 
responsividade a razões enquanto tais. É muito comum a contestação de que isto nos impediria de acomodar a maneira como animais nãoracionais adquirem conhecimentos sobre as coisas através de seus sentidos. Deverá ficar claro mais adiante que isto é um erro.

Alguém pode ter uma experiência que lhe revele que as coisas são de tal e tal modo, sem que venha a crer que as coisas são assim. Não é necessário que cada um de nós faça uso de todas as habilitações [entitlements] racionais que possui. Considere o caso de alguém está sendo enganosamente levado a desconfiar da própria experiência. Essa pessoa não acredita que a experiência esteja lhe revelando como as coisas são, mas, de fato, é exatamente isto que está ocorrendo.

A aquisição de uma crença que pode ser considerada racional à luz de uma certa experiência é um caso de racionalidade em funcionamento, ainda que, como procurei mostrar, este modo de operação da racionalidade não se enquadre numa estrutura que possa ser caracterizada como uma inferência. A crença é inteligível em termos de uma habilitação [entitlement] racional para ela que nos é dada pela experiência. E, uma vez que ter a experiência constitui uma habilitação [entitlement] racional para a crença, quer adquiramos ou não a crença à qual a experiência nos habilita, aquela mesma racionalidade deve estar em funcionamento na própria experiência que temos, ainda que não adquiramos a crença para a qual a experiência nos habilita. Assim, aplicando a estipulação a este caso: se nossa noção de experiência deve ser capaz de desempenhar o papel que ela desempenha quando explicamos crenças baseadas na percepção enquanto manifestações da racionalidade, devemos entender que ter uma tal experiência - estar em posse de tal habilitação - já é, em si mesma, uma realização das capacidades conceituais que seriam exercitadas por alguém que explicitamente adotasse uma crença com aquele conteúdo ${ }^{5}$.

Esse é um tipo de realização das capacidades conceituais cujos membros são casos de percepção, ou ao menos aparência de percepção, de que as coisas são de tal e tal modo. Quando explicamos a crença de alguém de que as coisas são de tal modo em termos do fato de que sua experiência meramente parece assim lhe revelar, nossa explicação está apresentando a crença como resultado de uma racionalidade que está induzindo ao erro quem a possui, ou, no melhor dos casos, dando-lhe 


\section{4}

uma crença que só é verdadeira por uma feliz coincidência. Mas, quando explicamos a crença de alguém de que as coisas são de tal e tal modo em termos de sua percepção de que as coisas são de tal e tal modo, nós estamos mostrando a crença como resultado desse tipo de operação da racionalidade em sua forma ideal.

5.

É importante que a conexão entre capacidades conceituais e racionalidade seja uma estipulação. Não é que haja uma idéia universalmente compartilhada de capacidade conceitual que determine um tema a respeito do qual as pessoas discordam. A noção do conceitual pode ser usada de várias maneiras, com vários propósitos.

É igualmente importante que a noção de responsividade a razões enquanto tais deixe espaço para a resposta a razões, ainda que não a razões enquanto tais, do outro lado da divisão entre animais racionais e animais que não são racionais. E responder a razões implica estar ciente daquilo a que se está respondendo ${ }^{6}$.

Se alguém quiser dizer que um animal, por possuir a fuga em seu repertório, está mostrando que possui o conceito de perigo, eu nem sequer preciso objetar. Isto é usar o conceito de conceito de uma maneira que não está de acordo com minha estipulação. Mas tudo estará bem, desde que levemos em conta essa divergência, e não a tomemos erroneamente por uma disputa substantiva acerca de um suposto tema comum.

Segundo essa outra maneira de falar, o conceito de perigo está presente em qualquer consciência, ou (para acomodar a possibilidade de erros) aparente consciência do perigo. E usar o conceito de conceito desta forma proporciona uma maneira de insistir numa boa tese: a de que, para ser capaz de estar ciente do perigo, um animal não precisa ser racional, no sentido que é constitutivo da divisão tradicional entre os animais racionais e os outros animais. Obviamente isto se generaliza para outros objetos da consciência animal.

Não vejo problema nenhum nisto. Como eu disse, trata-se de uma boa tese. Ela definitivamente contradiz a idéia de que, se a fuga de um animal não é resposta a uma razão enquanto tal, sua responsividade dife- 
rencial ao perigo não pode ser nada além de uma disposição responsiva, em um sentido que não é restrito às capacidades discriminadoras de seres sencientes. Nesta perspectiva, a responsividade diferencial ao perigo manifestada na capacidade de um animal em fugir não permitiria atribuir a ele a habilidade de estar ciente do perigo, não mais do que, digamos, a responsividade do aço à umidade à sua volta - uma disposição a enferrujar caso haja unidade e de não enferrujar caso não haja - permite supor que pedaços de ferro possam estar cientes da presença de umidade. ${ }^{7} \mathrm{Eu}$ penso que isto deve ser rejeitado logo de saída. Isto se choca com o senso comum no que diz respeito ao modo como o comportamento de animais vivos deve ser entendido.

Mas, para preservar o senso comum com relação ao estar ciente dos animais, não precisamos separar as capacidades conceituais da responsividade a razões enquanto tais. Minha estipulação não exige que a idéia de consciência não-conceitual seja denunciada. A restrição efetuada por minha estipulação aplica-se apenas ao estar ciente que figura nas operações da racionalidade no sentido exigente. E não há necessidade de supor que a capacidade de figurar nas operações de racionalidade é um elemento da idéia mesma do estar ciente ${ }^{8}$.

6.

Para uma objeção substantiva à concepção que propus de nossa experiência perceptiva, por oposição à mera divergência terminológica que acabei de discutir, precisamos considerar uma posição que aceite a identificação estipulativa de capacidades conceituais em termos de seu papel potencial no raciocínio, mas que coloque em questão minha afirmação de que capacidades conceituais, assim entendidas, estão operantes na nossa experiência perceptiva.

Muitas pessoas seguiram essa linha de raciocínio. Há uma incredulidade bastante comum que assume a seguinte forma: se alguém supõe, como eu faço, que o conteúdo de nossa experiência é conceitual, em um sentido no qual o conceitual está conectado com a racionalidade, não se pode fazer justiça à maneira sensorial pela qual a experiência perceptiva descortina a realidade para nós.

doispontos, Curitiba, São Carlos, vol. 3, n. 1, p.147-170, abril, 2006 
Com efeito, Michael Ayers, argumentando que o conteúdo da experiência sensorial, incluindo a nossa, é não-conceitual, enfatiza " a maneira como as coisas são apresentadas na experiência, o modo sensorial de apresentação...". Ele identifica a afirmação de que o conteúdo da experiência é não-conceitual com a afirmação - que ele representa como puro senso comum - "o mundo não está presente na experiência de um modo quase-lingüístico" (AYERS, 2004, p.249). Sua idéia é que, se nossa experiência fosse conceitual, ela apresentaria o mundo de uma maneira quaselingüística, e isto é inconsistente com o fato óbvio de que a experiência apresenta o mundo de uma maneira sensorial.

Mas o que eu recomendei foi uma concepção de nossa experiência como realização de capacidades conceituais na consciência sensorial. Adotar essa concepção de nossa experiência é aceitar, aliás insistir, que nossa experiência apresenta o mundo de maneira sensorial. Ayers está desautorizando a possibilidade mesma de supor, como eu faço, que um modo conceitual de apresentação poderia ser ele próprio um modo sensorial de apresentação.

Ayers equipara a afirmação de que nossa experiência tem conteúdo conceitual com a afirmação de que ela apresenta o mundo de uma maneira quase-lingüística. Isso poderia parecer justificar a exclusão da possibilidade de que um modo conceitual de apresentação pudesse ser um modo sensorial de apresentação. Mas, na medida em que a equiparação parece justificar a exclusão, ela é tendenciosa. O que está correto sobre a equiparação é o seguinte: é plausível que a habilidade de dar um passo para trás das considerações e questionar se elas constituem razões para a ação ou para a crença - habilidade que mencionei como um contexto necessário para capacidades conceituais no sentido de minha estipulação - seja concomitante à aquisição de uma linguagem. Assim, apenas falantes podem ter capacidades conceituais no sentido de minha estipulação. Mas isto não justifica a alegação de que minha concepção da nossa experiência representa o mundo experienciável como um texto ou, para usar a imagem de Arthur Collins, de que eu estou comprometido com um quadro no qual nossa experiência aparece, por assim dizer, legendada - como se a maneira conceitual através da qual, como afirmo, nossa experiência pretende desvelar o mundo para nós fosse uma característica extra, adicionada a seu caráter sensorial ${ }^{9}$. 
A imagem de Collins ajuda a tornar vívida uma forma específica freqüentemente assumida pela afirmação de que o conteúdo conceitual não pode acomodar a maneira sensorial de a experiência apresentar as coisas. Não há elaboração plausível dessa imagem na qual legendas poderiam capturar, digamos, todas as diferenças de tonalidade que a experiência normal das cores encontra no mundo visível. Mas isto não é problema para minha proposta, pois a imagem das legendas não se encaixa nela. Nossa experiência visual pode apresentar um tom de cor que é tão determinado quanto nossa habilidade de discriminar tonalidades pode fazê-lo. Uma tonalidade determinada está presente de maneira sensorial para a pessoa que tem uma tal experiência. Mas sua presença sensorial para essa pessoa consiste na operação de uma capacidade que pertence a sua responsividade a razões enquanto tais, e que, portanto, é conceitual no sentido da minha estipulação. Isto se reflete no fato de que ter a experiência é ter uma habilitação [entitlement] racional para a crença de que a coisa tem mesmo tal tom de cor. No caso ideal, trata-se de uma habilitação [entitlement] que equivale a colocar o sujeito em posição de saber, por meio de uma operação de sua racionalidade no sentido relevante, que a coisa tem mesmo aquele tom de cor $^{10}$.

Recusando-se a aceitar minha proposta de que realizações de capacidades conceituais podem apresentar as coisas de maneira sensorial, Ayers assume uma rígida separação entre o sensorial e o intelectual, como eu prefiro falar para evitar aquela implicação tendenciosa.

Mas tal separação não é incontroversa. Se um dualismo de intelecto e sentidos está sendo meramente assumido, torna-se uma petição de princípio usá-lo contra mim. E qual justificação pode existir para tal dualismo? É tomado como dado na tradição empirista, mas neste contexto dialético isto seria uma base pouco sólida para defendê-lo. Tanto pior para a tradição empirista, poderíamos dizer. Satisfazer-se com um dualismo do sensório e do intelectual revela uma falta de imaginação sobre as possibilidades de ver o intelecto racional integralmente envolvido nos fenômenos da vida humana ${ }^{11}$. Deveríamos argumentar na outra direção. Realizações de capacidades conceituais, capacidades que pertencem à racionalidade do sujeito que as possuem, podem apresentar as coisas de uma maneira sensorial, e isto desmente o dualismo. 
Donald Davidson, como todos sabem, afirmou que "nada pode contar como uma razão para se ter uma crença a não ser uma outra crença" (DAVIDSON, 2001, p.141)12. Objetei que isto não acomoda uma experiência que desempenhe seu papel de tornar as crenças racionalmente inteligíveis. Experiências não são crenças. Mas eu sugeri que podemos preservar um insight desse dito davidsoniano, afirmando que nada pode contar como razão para uma crença a não ser algo que tenha forma conceitual ${ }^{13}$.

Ayers objeta que não há nada que valha a pena preservar no slogan de Davidson. Todo tipo de coisa pode ser razão para uma crença. Uma fotografia pode ser a razão para uma crença sobre o assassinato de John F. Kennedy. Uma zebra percebida pode ser a razão para uma crença sobre a aparência das zebras. E assim por diante ${ }^{14}$.É claro que isto está correto com relação a um emprego bastante usual da noção de razão. Mas esta é uma vitória medíocre, que deixa intocado o espírito do slogan de Davidson.

Nos casos em que o slogan se aplica (casos que não incluem as crenças baseadas na percepção), Davidson obviamente não está afirmando que alguém baseia uma crença em suas crenças a respeito de alguma outra coisa - como se, no exemplo de Ayers, alguém concluísse que Kennedy foi morto por uma pessoa no solo, com base no fato ele acreditar que uma fotografia mostra alguém no chão atirando em Kennedy. É aquilo em que alguém acredita, e não o seu acreditar naquilo, que serve como razão para alguém no sentido que interessa a Davidson. E isto pode ser facilmente estendido de modo a que se ajuste ao fraseado preferido por Ayers. Nesse fraseado, descrevemos como razões coisas que pertencem ao tema das crenças que são razões no sentido de Davidson. Esse é o sentido no qual a fotografia é uma razão para uma crença sobre o assassinato.

Se fizermos abstração dos efeitos deste ponto-cego associado à possibilidade de atribuir à experiência um significado racional, podemos entender o slogan de Davidson na seguinte direção: as capacidades em funcionamento quando a racionalidade de alguém está operante devem ser capacidades que pertencem à sua racionalidade. Como isso poderia estar errado? Certamente alguém pode aduzir uma fotografia como evidência para uma crença sobre o assassinato, não apenas com estarda- 
lhaço, tentando persuadir outra pessoa, mas também enquanto está decidindo o que pensar. O ponto do slogan de Davidson não é negar isto, mas afirmar que a fotografia pode desempenhar esse papel, um papel em uma operação da racionalidade, apenas figurando no conteúdo de uma realização de capacidades que pertencem à racionalidade de alguém: isto é, capacidades que são conceituais no sentido da minha estipulação. Eu expliquei mais acima (no $\$ 4$ ) como esse núcleo abstrato do pensamento de Davidson está presente naquilo que precisamos dizer para reconhecer o significado racional da experiência, coisa que Davidson não faz. $\mathrm{O}$ lembrete de Ayers sobre o que ele chama (corretamente, se desconsiderarmos todo o resto) de "um tipo básico de apresentação de razão" (AYERS, 2004, p.243) não trata destas considerações. Ele as deixa completamente ilesas.

\section{8.}

Voltemos agora à conexão com o tema da criatividade.

Para introduzir a noção de racionalidade com a qual eu queria trabalhar, contrastei a fuga como o efeito imediato de um impulso natural com a fuga como o resultado de se decidir se uma circunstância que está tendendo a eliciar um impulso para fugir constitui uma razão suficiente para tal. No segundo caso, a fuga não é meramente voluntária, mas determinada pelo próprio agente. Generalizado, este contraste produz algo na seguinte direção: o que é especial sobre animais racionais é que eles são capazes de autodeterminação, no pensamento e na ação. Um animal racional tem a capacidade de estar no comando de sua própria vida, de viver de tal modo que sua vida seja algo que ele mesmo produz. Se uma vida é conduzida com a liberdade que a racionalidade torna possível, tem sentido comparála com uma obra de arte que o sujeito está engajado em criar.

É claro que o que a racionalidade confere é apenas a capacidade de viver uma vida que nos pertence no sentido para o qual estou acenando. Em que extensão a capacidade é exercitada, e em quais regiões da vida, é algo que depende de uma série de fatores. As condições sob as quais o potencial para a liberdade pode ser realizado são um tópico importante para a filosofia. 
O que propus é que as capacidades que pertencem a essa potencialidade especial dos animais racionais, capacidades para autodeterminação no pensamento, estão essencialmente envolvidas na aquisição, pelos animais racionais, de crenças baseadas na percepção.

Precisamos ter cuidado com relação a como a idéia de uma capacidade de estar no comando da própria vida se aplica neste contexto. Uma vez que alguém determinou coisas tais como a direção de seu olhar, não está mais sob seu controle aquilo que sua experiência se põe a revelar a respeito do modo como as coisas são. Além disso, felizmente não concebemos o surgimento de uma crença com base na experiência como uma decisão que tomamos a respeito daquilo que vamos pensar. É verdade que existem casos em que, com maior ou menor esforço, alguém pode recusar-se a aceitar que as coisas são como elas, digamos, parecem ser. Se alguém está familiarizado com a ilusão de Müller-Lyer, ela inibe a tendência a julgar que uma das duas linhas é maior que a outra, mesmo que, por mais familiarizados que estejamos com a ilusão, uma linha continue sempre parecendo ser maior. Mas a experiência perceptiva pode trazer fatos à luz do dia. E, mesmo quando se diz isso de maneira apropriada, seria absurdo falar em decidir o que pensar como se estivéssemos fazendo uma opção. Não escolhemos aceitar que as coisas são da maneira como nossa experiência diretamente nos revela que elas são.

Poderíamos reformular isto dizendo que há um sentido em que a experiência perceptiva pode compelir à crença. Mas, como as capacidades para autodeterminação racional estão em funcionamento quando estamos sujeitos a esta compulsão, isso não significa uma ameaça ao controle racional da própria vida. Compare o sentido em que podemos estar compelidos a aceitar a conclusão de um argumento convincente com cujas premissas estamos irremediavelmente comprometidos. Não sacrificamos nossa liberdade quando aquiescemos à autoridade daquilo que reconhecemos como razões persuasivas. Reconhecer razões como persuasivas já é um exercício das próprias capacidades para autodeterminação racional. Se alguém não oferece resistência alguma quando suas crenças tomam a forma que a razão exige que elas tomem, não está entregando aquela região de sua vida a uma força alheia. Não está abdicando da responsabilidade de manter um controle racional sobre seu próprio pensamento ${ }^{15}$. 
Ayers contrapõe-se à idéia de que o empirismo não pode atribuir à experiência perceptiva um conteúdo que vá além das sensações. Ele evoca uma posição com "uma respeitável ancestralidade empirista" (ele cita Hobbes), de acordo com a qual "o que é 'dado' na sensação de uma luz verde brilhando... é apenas isto, uma luz verde brilhando". Os próprios estados sensoriais de quem percebe já têm conteúdo intencional, e o sentido no qual crenças perceptivas estão fundamentadas na sensação é que elas derivam seu conteúdo intencional do conteúdo intencional dos estados sensoriais nos quais elas se baseiam. "Deste ponto de vista, acreditar nos próprios sentidos é exatamente isso. Não há inferência envolvida, e não há intermediário. Nós apenas aceitamos o que os sentidos conjuntamente nos dão" (AYERS, 2004, p.241) ${ }^{16}$.

Eu penso que essa é apenas a forma que um empirismo aceitável deve ter. É precisamente para abrir espaço para uma imagem com essa forma que eu defendo a concepção de nossa experiência à qual Ayers resiste. É precisamente para dar sentido à idéia de que a experiência perceptiva pode abrir-nos diretamente ao mundo que eu afirmo que devemos ver a experiência como uma realização de capacidades conceituais, capacidades que pertencem a nosso caráter especial enquanto animais racionais.

Como eu expliquei, isso não significa negar que animais não-racionais se tornem informados ou desinformados, através de seus sentidos, sobre traços da realidade que interessam a eles. Significa apenas insistir em uma diferença entre isto e vir a conhecer coisas através da percepção como nós fazemos, em uma operação da racionalidade no sentido forte de responsividade a razões enquanto tais.

Animais não-racionais tornam-se informados ou desinformados através do funcionamento não-mediado de seus sentidos. Se alguém achasse apropriado descrevê-los como seres que acreditam em seus sentidos ou que aceitam o que seus sentidos thes dão, esse alguém estaria utilizando mal as palavras. Este modo de falar é apropriado para descrever a formação de crenças por sujeitos que podem recusar-se a acreditar em seus sentidos - formação de crenças que pode ser entendida como racionalidade (no sentido de responsividade a razões enquanto tais) em funcionamento. 
Conforme já insisti, ver nossa aquisição de crenças perceptivas como racionalidade em funcionamento não implica que sempre chegamos a tais crenças decidindo o que pensar. Normalmente chegamos sem qualquer reflexão a nossas crenças baseadas na percepção. Mas o que fazemos sem reflexão só pode ser descrito como uma crença em nossos sentidos ou como aceitação daquilo que eles nos transmitem porque é uma manifestação da nossa racionalidade no sentido relevante e, por conseguinte, como expliquei, uma realização de capacidades que pertencem a nosso entendimento racional, capacidades que não compartilhamos com animais não-racionais.

\section{0.}

A resistência de Ayers à idéia de que capacidades conceituais estão operantes em nossa experiência perceptiva é largamente motivada por sua hostilidade ao idealismo, em cuja direção ele acha que somos levados.

Há alguma justiça na opinião de que tal idéia parecer funcionar apenas num contexto idealista. Penso que isto é central para um suposto fundamento que muitas pessoas, e não apenas Ayers, teriam para não acreditar que capacidades pertencentes essencialmente a nosso potencial para autodeterminação possam estar em atividade em nossa recepção sensorial da realidade. Mas aqui precisamos de uma distinção que Ayers não leva em conta.

Qualquer idealismo com chance de ter crédito deve aspirar a ser tal que, quando examinado a fundo, ele se revele totalmente coerente com o realismo do senso comum ${ }^{17}$. Kant, por exemplo, tem essa aspiração para seu idealismo transcendental. Isto fica evidente em sua alegação de que esse idealismo coincide com o realismo empírico. Contudo, por causa da maneira como trata as formas da sensibilidade, ele não consegue se dar o direito de fazer tal afirmação. Em sua imagem, o mundo tal como o experienciamos parece, no que diz respeito à sua aparente organização espacial e temporal, ser um mero reflexo de traços autônomos de nossa subjetividade. Deste modo, o objetivo de coincidir com o realismo fracassa.

É claro que fracassos particulares não podem solapar a idéia mesma de um idealismo que coincida com o senso comum. Ayers, no entanto, não 
pode ver coisa alguma que o idealismo poderia ser, a não ser uma posição que representa traços da estrutura da (poderíamos dizer, assim chamada) realidade como projeções de características de uma subjetividade autosuficiente, como o idealismo de Kant faz, a despeito de suas aspirações.

Em Mente e Mundo, tentei mostrar que o conteúdo conceitual de uma experiência perceptiva pode ser, se tudo ocorre bem, algo que é o caso, um elemento do mundo. Nós podemos ver a experiência como uma internalização direta de parte do mundo, pois o mundo, entendido como tudo o que é o caso, não está fora da esfera do conceitual. Eu digo que isto pode parecer "um tipo de idealismo, no sentido em que chamar uma posição de 'idealismo' é declarar que ela não comporta um reconhecimento genuíno de que a realidade é independente de nosso pensamento" (MCDOWELL, 1994, p.26). Mas eu luto para desfazer tal aparência.

Ora, Ayers cita parte da passagem que eu acabei de citar. Mas ele termina sua citação antes da glosa na qual eu especifico o tipo de idealismo que eu quero rejeitar ${ }^{18}$. Evidentemente ele acha que tal glosa é redundante; da maneira como ele vê as coisas, o idealismo é apenas uma posição que reconhece insuficientemente a independência da realidade.

Isso tem conseqüências. Quando eu rejeito a acusação de que represento o mundo como uma projeção de nossa subjetividade, Ayers pensa que eu devo estar negando que "a forma do juízo estrutura o mundo tal como ele é experienciado e conhecido" (AYERS, 2004, pp.254-255). Ele acha que eu devo conceber o mundo como algo que se coloca diante de nosso pensamento e de nosso discurso numa relação que seria a contraparte em grande escala da relação que, digamos, uma zebra poderia ter com nosso pensamento e nosso discurso a respeito dela. Uma zebra pode ser descrita, mas isto não é razão para supor que a própria zebra tenha uma forma que ela compartilha com a descrição, ou com o pensamento que a descrição expressa. Ayers pensa que eu penso que com o mundo acontece exatamente a mesma coisa (qualquer outra coisa seria idealismo, e eu me declarei contrário a isso). Então, se o que eu digo sobre o mundo é "nada mais do que uma maneira de expressar a trivialidade de que o mundo e as coisas que estão nele são descritíveis" (AYERS, 2004, p.253), Ayers não consegue ver como eu posso desaprovar um movimento paralelo com relação à experiência. Sem dúvida o que a experiência nos dá pode ser expresso em uma forma proposicional ou conceitual, mas não 


\section{4}

há razão para supor que a experiência ela mesma possua uma forma conceitual, assim como as zebras não possuem, e em conseqüência assim também como o mundo não possui, na concepção que ele pensa encontrar em mim.

Aqui Ayers foi levado a uma leitura errônea por assumir que qualquer noção de mundo que o apresente conceitualmente estruturado deve implicar o que eu explicitamente rejeito - que o mundo seja um mero reflexo de uma subjetividade auto-suficiente. Na passagem que ele está considerando, eu discuto a observação de que "o mundo é tudo que é o caso" - a primeira observação feita no Tractatus. Eu insisto que não devemos tomar isto como a expressão de "uma grande visão ontológica ou metafisica"(AYERS, 2004, p.252), para usar as palavras de Ayers. Eu afirmo que deveríamos entender essa observação como se ela expressasse truisticamente o conteúdo de uma maneira inobjetável de usar a noção de mundo. Não estou afirmando, como Ayers supõe, que deveríamos de alguma forma não querer dizer isto quando dizemos que o mundo é tudo aquilo que é o caso. E, se nós dizemos isso, e queremos de fato dizêlo, concebemos o mundo, não da maneira como Ayers acha que eu devo concebê-lo, como a totalidade das coisas passíveis de descrição - zebras e assim por diante - que nele existem (conforme dizemos), mas precisamente como tudo o que pode ser pensado ou dito e que, além disso, é verdadeiro: não tudo sobre o que poderíamos pensar se pensássemos com verdade, mas tudo o que poderíamos pensar.

Isso é idealismo em um sentido óbvio. Nesta concepção, o mundo ele mesmo é de fato estruturado pela forma do juízo. Eu não descrevo essa concepção como um idealismo em meu livro, onde considero apenas idealismos do tipo que eu especifico na nota que Ayers omite - posições que reconhecem insuficientemente a independência da realidade. Mas o rótulo se encaixa bem.

Como eu disse, Ayers pensa que a especificação de um tipo de idealismo é redundante. Ele assume que não se pode igualar a forma do mundo e a forma do pensamento sem representar a realidade como uma sombra de algo auto-suficientemente subjetivo. Mas isso depende de assumir que em qualquer posição desse tipo a forma do pensamento deve ser entendida como algo que pode ser explicado de antemão, antes mesmo de considerarmos a relação do pensamento com a realidade, e 
apenas numa etapa subseqüente ser dito que essa forma coincide com a forma do mundo. Segundo este modo de ver as coisas, a forma cumpre seu papel formatando o pensamento, que é certamente subjetivo, antes que se possa afirmar que ela também formata a realidade. E então a afirmação de que ela formata a realidade assemelha-se a uma projeção, naquilo que é considerado objetivo, de algo que originalmente ajustavase ao âmbito subjetivo. Mas se dizemos que o mundo é tudo o que pode ser verdadeiramente pensado como sendo o caso, nós não permitimos que se entenda uma tal coisa. A imagem de uma projeção de uma subjetividade auto-suficiente não tem lugar se insistirmos, como devemos, que o pensamento e o mundo devem sem entendidos juntos. A forma do pensamento já é, tomada enquanto tal, a forma do mundo. É uma forma que é subjetiva e objetiva ao mesmo tempo, não primeiramente subjetiva e em seguida supostamente objetiva - uma ordem de prioridade que desmascararia sua afirmação de ser objetiva como espúria exatamente no sentido que Ayers tem em vista.

Aqui temos, ao menos programaticamente, um idealismo que não diverge do realismo do senso comum. Dada sua pretensão de se conformar ao senso comum, é conveniente que o slogan que expressa este idealismo - "O mundo é tudo o que é o caso" - deva ser um truísmo, como eu disse, e não uma expressão de alguma metafísica contenciosa ${ }^{19}$.

Pode ser tentador protestar que se o idealismo que eu tenho em vista deve coincidir com o senso comum, nós podemos da mesma forma prendermo-nos ao senso comum. Mas, na medida em que prestamos atenção na maneira como os animais racionais são marcados como seres especiais por seu potencial para autodeterminação, precisamos reconhecer que nossa racionalidade tem o seu quinhão na possibilidade de descrevermos a nós mesmos como seres que aceitam aquilo que nossos sentidos nos dão. Como eu disse, tais locuções não se aplicam a qualquer criatura informada pelos sentidos a respeito das coisas. E o idealismo vai diretamente ao ponto quando explica como tais locuções funcionam - como nossos sentidos nos dão algo para aceitarmos, de tal modo que, nos casos ideais, nós internalizamos diretamente uma parte do mundo objetivo.

Isso, por outro lado, contribui para tornar não-misterioso o fato de que capacidades para as quais é essencial poderem ser exercidas na autodeterminação podem ser capacidades para o pensamento em geral, 
com todo o peso objetivo que isso envolve. Mas não estava em meus planos tratar desse problema neste artigo, e eu não me estenderei mais sobre ele aqui.

${ }^{1}$ Este texto é uma versão modificada da conferência pronunciada em 28 de outubro de 2005, no Departamento de Filosofia da Universidade de São Paulo. Tradução de Herivelto Pereira de Souza.

${ }^{2}$ Ver Mind and World, Cambridge: Harvard University Press, 1994; second edition, 1996 (trad: Mente e Mundo. São Paulo: Idéias \& Letras, 2005). E "Having the world in view: Sellars, Kant and intentionality", Journal of Philosophy, 1998.

${ }^{3}$ KANT, I. Critique of Pure Reason, traduzido por Norman Kemp Smith, London 1929. [trad: Crítica da razão pura. São Paulo: Abril Cultural, 1980.]

${ }^{4}$ Esta formulação abre espaço para o reconhecimento de que a experiência tem um conteúdo que ultrapassa aquilo que é evocado na explicação da crença.

5 Claramente estou usando o termo "habilitação" [entitlement] como Tyler Burge o usa, em "Perceptual entitlement", Philosophy and Phenomeological Research, 2003. Burge não insere a habilitação no contexto de uma noção de racionalidade autodeterminante. De fato, ele se opõe à divisão tradicional entre animais racionais e não-racionais, que ele acusa de levar a uma "hiperintelectualização" (503-4). Surpreendentemente, Burge escreve $(504$, n. 1) como se sua "introdução" da "habilitação" usada desta maneira, em artigos de 1993 e 1995, lhe tivesse dado algum tipo de patente sobre o termo, de modo que ele reclama que diferentes usos deste são "indiscriminados". Meu uso não é indiscriminado, e a palavra, corriqueira no inglês, é propriedade de todos. Ela pode ser usada de modo completamente natural em qualquer epistemologia "normativa". Eu considerarei a acusação de "hiperintelectualização" em uma nota posterior.

${ }^{6}$ A idéia geral aqui é que a ênfase na distinção entre animais racionais e não-racionais é consistente com a insistência em uma continuidade substancial sobrepondo-se à divisão. Burge, em "Perceptual entitlement", parece esquecer esta possibilidade. Isto está subjacente à falta de entendimento que ele demonstra, nas pp. 526-30, quando se refere a Wilfrid Sellars e a filósofos influenciados por ele.

7 Considere a explicação de Robert Brandom para o conhecimento observacional. A explicação dele implica que se nós partirmos das capacidades para o conhecimento observacional e subtrairmos as capacidades conceituais, no sentido relevante que pode ser explicado em termos de uma conexão com a racionalidade, o que resta não é nada senão confiáveis disposições responsivas diferenciais - um tipo de disposição possuída não apenas por animais, mas também por objetos inanimados tais como termômetros ou limaduras de aço.Ver o capítulo 4 de Robert B. Brandom, Making It Explicit: Reasoning, Representing and Discoursive Commitment, Cambridge: Harvard University Press, 1994.

${ }^{8}$ Michael Ayers, em "Sense experience, concepts, and content - objections to Davidson and McDowell”, em Ralph Schumacher, ed., Perception and Reality: From Descartes to the Present,

doispontos, Curitiba, São Carlos, vol. 3, n. 1, p.147-170, abril, 2006 
Paderborn: Mentis, 2004, diz que estou equivocado com relação à consciência perceptiva de animais não-racionais (ver p. 239; a afirmação é expandida na p. 261. Ayers diz que meu pensamento tende em direção a uma visão cartesiana dos “animais", mesmo que - o outro lado de minha suposta postura equivocada - minha exposição esteja "ornamentada com retratações"). Isto é um reflexo do fato de ele achar uma obviedade que animais racionais e animais não-racionais devem ter consciências perceptivas de um mesmo tipo. O resultado é que quando eu nego que animais não-racionais têm, no sentido da consciência perceptiva, o que nós temos, ele ouve esta afirmação de tal modo que ela passa a implicar que animais nãoracionais não têm consciência perceptiva alguma. Este é um exemplo dos efeitos maléficos de se projetar nossa própria concepção do que seja óbvio quando lemos um outro autor. Isto pode nos tornar incapazes de ouvir o que o outro está dizendo. E é uma prática especialmente ruim quando, como neste caso, o objetivo da leitura é precisamente questionar o sentido daquilo que condiciona a leitura. A sugestão de Ayers de que meu pensamento tende a uma negação cartesiana da consciência a animais não-racionais é desprovida de fundamento.

${ }^{9}$ Ver Arthur W. Collins, "Beastly experience", Philosophy and Phenomenological Research, 1998, p. 379. Sobre a idéia de realidade experienciável como um texto, ver Ayers, "Sense experience, concepts, and content", p. 251, n. 23.

10 Em Mind and World (pp. 56-60), associei estas capacidades conceituais finas à habilidade de capturar uma tonalidade de cor (digamos) usando uma expressão demonstrativa cujo significado depende de uma experiência na qual algo é visto como tendo aquele tom de cor. Eu escrevi a respeito de expressões como "aquela tonalidade". "Colorida assim" teria sido melhor, por razões que surgem em minha resposta a Christopher Peacocke em "Reply to commentators", Philosophy and Phenomenological Research, 1998, pp. 414-7. Ayers, em "Sense experience, concepts, and content" (p. 260), afirma que, neste tipo de abordagem, a tonalidade deveria ser apresentada na experiência independentemente de uma capacidade conceitual cujo conteúdo poderia receber expressão lingüística daquela maneira; ela deveria, então, ser apresentada não-conceitualmente na experiência. Mas não há base para se afirmar isto. Certamente a tonalidade deve estar presente de alguma forma na experiência, pois sua presença é capaz de ajudar a determinar o significado da expressão demonstrativa. Mas isto é consistente com o fato de sua presença na experiência ser a operação de uma capacidade conceitual - uma capacidade conceitual que, graças à presença da tonalidade na experiência (isto é, graças a essa operação da capacidade conceitual que ela é), pode ser capturada pela expressão demonstrativa. As impressões de Ayers vão no sentido contrário, e dependem de um mau tratamento da conexão entre capacidades conceituais e linguagem. Na verdade, ele está deixando que a imagem das legendas o confunda. Ele procede como se eu tivesse que supor que o conteúdo em questão adquire uma forma conceitual apenas quando a linguagem é de fato usada, naquela forma demonstrativa, para expressá-lo. A inteligibilidade da forma demonstrativa requereria que o conteúdo já estivesse lá - conseqüentemente, nesta perspectiva, antes do conteúdo adquirir forma conceitual. Mas, para que o conteúdo seja conceitual, basta que ele possa ser colocado em uma expressão lingüística desse tipo. Ele não se torna conceitual apenas quando de fato lhe é dada expressão lingüística.

11 Burge pensa que enfatizar a racionalidade autodeterminante dos animais racionais leva a uma "hiperintelectualização" em epistemologia ("Perceptual entitlement", pp. 503-4). Mas a insistência no caráter especial dos animais racionais só leva ao excesso de intelectualismo que

doispontos, Curitiba, São Carlos, vol. 3, n. 1, p.147-170, abril, 2006 


\section{8}

ele corretamente critica se vier unida a uma separação dualista entre o intelecto racional e os sentidos, ou, de modo mais genérico, entre o intelecto racional e os dotes cognitivamente relevantes que temos em virtude da nossa natureza animal. A acusação não se encaixa naquilo que venho defendendo. Sem o dualismo, não precisamos desconsiderar as "normas" cognitivas biologicamente ancoradas que Burge discute. Elas certamente são relevantes para entender as normas que governam a conduta cognitiva de animais racionais. Mas não incorreremos numa "hiperintelectualização" se insistirmos em que estar sujeito a estas últimas normas é característico de uma cognição cuja natureza é categorialmente diversa.

12 "A coherence theory of truth and knowledge", republicado em Donald Davidson, Subjective, Intersubjective, Objective, Oxford: Clarendon Press, 2001, p. 141.

${ }^{13}$ Ver Mind and World, p. 141, pp. 143-4.

${ }^{14}$ Ver "Sense experience, concepts, and content", pp. 243-4, pp. 248-9.

15 Richard Rorty sugere que a concepção do pensamento como responsável perante seu objeto representa o mundo como uma contrapartida secular de uma divindade autoritária. Ver, por exemplo, "Solidarity or objectivity?", em seu Objectivity, Relativism and Truth, Cambridge: Cambridge University Press, 1991; [trad.: Solidariedade ou objetividade?, em Objetivismo, relativismo e verdade: escritos filosóficos I. Rio de Janeiro: Relume-Dumará, 1997.]; e "The very idea of human answerability to the world: John McDowell's version of empiricism”, em seu Truth and Progress: Philosophical Papers, vol. 3, Cambridge: Cambridge University Press, 1998 [trad.: A verdadeira idéia da capacidade do ser humano de responder ao mundo: a versão de John McDowell sobre o empirismo, em Verdade e progresso. Barueri: Manole, 2005.]. Seu objetivo é mostrar que, se considerarmos a objetividade como um ideal constitutivo do pensamento, desrespeitamos a obrigação de pensar por nós mesmos, que é parte do conteúdo da obrigação de viver a própria vida. Eu penso que as considerações esboçadas aqui mostram que esta posição de Rorty depende de uma interpretação equivocada da obrigação de pensar por si mesmo. A obrigação de pensar por si mesmo não pode requerer a emancipação do pensamento de ser controlado por boas razões. E quando uma experiência nos revela como as coisas são, estamos em posse de uma razão excelente para pensar que as coisas são daquela maneira. Rorty está certo em recusar diversas formas extremadas de realismo, mas ele está errado em deixar que isso o leve a um ataque indiscriminado a todas as formas que pode assumir a idéia de que a objetividade é uma meta constitutiva do pensamento.

16 Todas a citações neste parágrafo são tiradas de "Sense experience, concepts, and content", p. 241.

17 Em Notebooks 1914-1916, Oxford: Blackwell, 1961, 85, Wittgenstein escreve que "idealismo leva ao realismo se pensado em todas as suas conseqüências". No Tractatus Logico-Philosophicus, London and Henley: Routledge and Kegan Paul, 1961, [trad.: Tractatus Logico-Philosophicus. São Paulo: Edusp, 1993.], 5.64, a coincidência com o realismo é diretamente atribuída ao solipsismo, o qual figura na rota do idealismo ao realismo no Notebooks.

18 "Sense experience, concepts, and content", p. 252.

${ }^{19}$ Ayers lê equivocadamente o que ele chama de "tagarelice quietista de McDowell" (p. 253). Ele pensa que o sentido da "tagarelice quietista" é me tornar apto a não querer dizer o que digo quando falo que o mundo é conceitualmente estruturado. ("Nós não devemos supor

doispontos, Curitiba, São Carlos, vol. 3, n. 1, p.147-170, abril, 2006 
que a fala sobre 'fatos' queira dizer que o mundo... tem uma forma literalmente proposicional..." [p. 254].) Mas eu quero dizer isso mesmo; o propósito da "tagarelice quietista" não é recusar a afirmação de que o mundo é conceitualmente estruturado, mas insistir que ela não expressa algo metafisicamente contencioso. A cegueira de Ayers à possibilidade de um idealismo que é, quando convenientemente entendido, não-contencioso - sua convicção de que qualquer idealismo não pode senão depreciar a independência da realidade - o leva, na p. 255, a afirmar que é "metafisica ruim" supor que o mundo tal como o experienciamos se divide em fatos. Ele pensa que este é o topo de uma ladeira escorregadia em cujo fundo está a idéia de que a assim chamada realidade é uma projeção do pensamento. (Ver também pp. 248-9.) Ele insiste, aqui, no pensamento contrastante de que "o mundo, na escala em que nós o experienciamos, é em certa medida dividido em objetos materiais unitários, e é assim que nós o experienciamos". Vale a pena notar que isto não se coaduna com a sua aprovação, na p. 241, da idéia de que "nós apenas aceitamos o que os sentidos nos dão em conjunto". O que faz sentido dizer que aceitamos são supostas revelações feitas pelos sentidos de como as coisas são. Nós não aceitamos objetos materiais unitários; nós aceitamos, digamos assim, que somos confrontados por eles.

\section{Referências bibliográficas}

AYERS, M. 2004. "Sense experience, concepts, and content objections to Davidson and McDowell". In: Ralph Schumacher, ed. Perception and Reality: From Descartes to the Present, Paderborn, pp. 239-62.

BRANDON, R.B. 1994. Making It Explicit: Reasoning, Representing, and Discursive Commitment, Cambridge: Mass.

BUR GE, T. 2003. "Perceptual entitlement". In: Philosophy and Phenomenological Research, pp. 503-48.

COLLINS, A. 1998. "Beastly experience", Philosophy and Phenomenological Research, pp. 375-80.

DAVIDSON, D. 2001. "A coherence theory of truth and knowledge", in Davidson, Subjective, Intersubjective, Objective, Oxford University Press, pp. 137-57.

KANT, I. 1929. Critique of Pure Reason, translated by Norman Kemp Smith, London: Bedford Books.

MCDOWELL, J. 1998. "Having the world in view: Sellars, Kant, and intentionality", Journal of Philosophy (1998), pp. 431-91. 
1998. "Reply to commentators", Philosophy and

Phenomenological Research (1998), pp. 403-31.

RORTY, R. 1991. "Solidarity or objectivity?", in Rorty, Objectivity,

Relativism, and Truth, Cambridge University Press, pp. 21-34.

1998. "The very idea of human answerability to the world:

John McDowell's version of empiricism”, in Rorty, Truth and Progress:

Philosophical Papers, vol. 3, Cambridge University Press, pp. 138-52.

WITTGENSTEIN, L. 1961. Notebooks 1914-1916, Oxford University Press.

, L. 1961. Tractatus Logico-Philosophicus, London and

Henley. 